DOI: 10.2478/atd-2021-0009

\title{
Improving Primary School Students' Creative Writing and Social-Emotional Learning Skills through Collaborative Digital Storytelling
}

\author{
Ali Uslu - Nilüfer Atman Uslu* \\ Received: June 6, 2020; received in revised form: September 29, 2020; \\ accepted: October 4, 2020
}

\begin{abstract}
:
Introduction: It is stated that digital storytelling (DST) involves a process in which students develop many skills such as searching for information, writing scripts, organisation, presentation, communication and problem solving (Robin, 2006). In this process, it is seen that recent studies have started to focus on collaborative digital storytelling (CDST) to support students (Liu, Huang, \& Xu, 2018; Nishioka, 2016; Perez, Martinez, \& Pineiro, 2016; Perez, Martinez, \& Pineiro, 2018; Rubino, Barberis, \& Malnati, 2018). Building a digital story as an artefact with a group and examining its effect on creative writing skills can help gain insight into the potential of the CDST. Also, it can be stated that CDST has the potential to provide a suitable environment for social-emotional learning skills. In this regard, this study aims to examine the effect of collaborative digital storytelling on the creative writing and social-emotional learning skills of elementary school fourth grade students.

Methods: In the study, a quasi-experimental design, was used, with pretest and post-test control groups. A process in which the experimental group was assigned a collaborative digital story, and the control group the task of preparing a visual presentation was designed. 60 students attending the fourth grade of a primary school participated in the study. The control group consisted of 30 students (14 females and 16 males), and the experimental group was also 30 students ( 15 female and 15 male students). The research was carried out in the 2017-2018 academic year and the implementation process lasted 11 weeks. Writing activities of the students were scored with the Creative Writing Rubric developed by Öztürk
\end{abstract}

\footnotetext{
* Ali Uslu, Celal Şükrü Sarısoy Elementary School, Alaşehir, Manisa, Turkey; aliuslu4507@gmail.com

Nilüfer Atman Uslu, Celal Bayar University, Department of Computer Education and Instructional Technology, Manisa, Turkey; atmanuslu@gmail.com
} 


\section{Acta Educationis Generalis \\ Volume 11, 2021, Issue 2}

(2007). The Creative Writing Rubric is composed of eight sub-dimensions: (a) originality of ideas, (b) fluency of thoughts, (c) flexibility of thoughts,

(d) word richness (selection), (e) sentence structure, (f) organisation (introduction to writing, development and outcome), (g) writing style, (h) compliance with grammar rules. The Social-emotional Learning Skills Scale developed by Kabakçı and Owen (2010) was used to measure socialemotional learning skills. There are 40 items on a 4-point Likert scale which consists of four factors: problem solving, communication, increasing self-value and coping with stress. In the study, paired samples ttest and single factor ANCOVA analysis were used and effect size ( $\eta 2)$ and Cohen's d were calculated.

Results: According to the t-test results for dependent groups, an increase between pre-test and post-test scores was found significant for creative writing in both the experimental $(\mathrm{t}(29)=8.623 ; \mathrm{p}=0,000)$ and the control group $(\mathrm{t}(29)=5.259 ; \mathrm{p}=0,000)$. When the calculated effect size values are examined, it is seen that there is a large effect size for the experimental group (Cohen's $\mathrm{d}=0.88$ ) and a medium (Cohen's $\mathrm{d}=0.54$ ) for the control group (Cohen, 1988). For social-emotional learning skills, a statistically significant difference was found between pre-test and post-test scores in both experimental $(\mathrm{t}(29)=2.518 ; \mathrm{p}=0.018)$ and control groups $(\mathrm{t}(29)=$ 3.934; $\mathrm{p}=0.000)$. The effect size is small for both in the experimental (Cohen's $\mathrm{d}=0.42$ ) and control groups (Cohen's $\mathrm{d}=0.42$ ) for socialemotional learning. When pre-test scores were kept constant, a single factor covariance analysis (ANCOVA) was conducted to examine whether the collaborative digital story preparation process had a significant effect on the post-test scores of the groups. According to the ANCOVA results, there was a significant difference between the creative writing post-test scores of the groups, $F(1,57)=7.09, p<0.05$. In other words, the experimental process had an impact on creative writing. It is seen that the effect size value is calculated as $\eta 2=0.111$. According to the ANCOVA results, there was no significant difference between the social-emotional learning skills post-test scores of the groups, $\mathrm{F}(1,57)=0.137, \mathrm{p}>0.05$.

Discussion: When the experimental and control groups were compared, it was concluded that the experimental process had a moderate effect in favour of the experimental group on the creative writing skill. When the related literature is examined, studies-support these results. Schmoelz (2018) stated that the specific stages of digital storytelling are very important for providing co-creativity, especially the story production stage enables the co-creative flow experience. According to Daigle (2008), digital storytelling requires writing skills and creativity. It can be used effectively where DST is considered as a means of developing narrative knowledge (Garcia \& Rossiter, 2010). When the social-emotional learning skills were examined, it was seen that there was an improvement in both the experimental group and the control group when the implementation process was completed. However, it was concluded that the experimental process did not have a significant effect on social-emotional learning skills. This may be because the students in both groups performed a 


\title{
Acta Educationis Generalis \\ Volume 11, 2021, Issue 2
}

\begin{abstract}
collaborative study. Future studies may focus on an in-depth understanding of the process by conducting a qualitative study within the context of CDST and social-emotional learning skills. As a result of this study, it can be concluded that CDST improved students' creative writing skills and can be used in language lessons.

Conclusions: In the study, it was observed by the researchers that CDST was more advantageous in terms of time and application. Future research may focus on comparing individual and collaborative digital storytelling. Other research may examine the effect of CDST on the attitudes of students towards collaborative work. This study was designed with a quantitative method, and research can be conducted in the future using a qualitative or mixed method that addresses students' experiences, difficulties, teachers and parents' views in the process.
\end{abstract}

Key words: collaborative digital storytelling, creative writing, socialemotional learning.

\section{Introduction}

In recent years, it is seen that the knowledge and the skills that the future workforce should possess have been updated as a reflection of the developments in technology. These competencies are addressed under three headings: foundational literacies, competencies, character qualities (World Economic Forum, 2015). In this context, students are expected to have competencies such as problem solving, creativity, communication and collaboration in addition to core skills that include various kinds of literacy. Moreover, character traits such as curiosity, persistence, leadership and social-cultural awareness are addressed. According to the report of the World Economic Forum titled "The Future of Jobs" (2016), creativity and emotional intelligence are among the top ten skills of the future. In addition to the economic function of education, it is important to acquire these competencies within the scope of the individual's selfempowerment and wellness. In order to gain these skills, digital storytelling (DST) has the potential to encourage the individual in productive and creative technology use. DST is defined as the story creation process, with digital tools including interactive and multimedia technologies (Rubino et al., 2018). DST is considered a work in which all people share their experiences in a certain digital format and provide production and sharing together (Şimşek, Usluel, Sarıca, \& Tekeli, 2018). According to Daigle (2008), the DST process incorporates visual, auditory and kinesthetic approaches to learning, while combining personal experience as a story of writing experience. DST fosters learners' 'autonomy while structuring students' evolving identities and experiences (Grigsby, TheardGriggs, \& Lilly, 2015).

In recent years, there has been an increase in the use of DST in the educational context, and studies have been carried out in this regard. The effect of DST on 
many variables such as academic performance (Çiçek, 2018; Gömleksiz \& Pullu, 2017; Yang \& Wu, 2012), problem-solving skills (Hung, Hwang, \& Huang, 2012), critical thinking (Yang \& Wu, 2012), emotional intelligence (Pieterse \& Quilling, 2011), writing skills (Sarıca \& Usluel, 2016), language learning (Kurudayığlu \& Bal, 2014; Yoon, 2013), have been examined in the last decade. It is also stated that sharing the digital stories provides a neutral environment where students feel safer, which offers a number of advantages compared to traditional storytelling (Duveskog, Tedre, Sedano, \& Sutinen, 2012). Robin (2006) described DST as involves a process in which students develop many skills such as searching for information, writing scripts, organisation, presentation, communication and problem solving. In this process, recent studies have started to focus on collaborative digital storytelling to support students (Liu et al., 2018; Nishioka, 2016; Perez et al., 2016; Perez et al., 2018; Rubino et al., 2018). CDST is considered an effective strategy that supports students' skills and competences (Perez et al., 2018). Collaborative work can help students develop language skills and collaborative work skills by allowing them to rehearse specific assignments with their peers (Laborda, 2009). Collaborative story writing can support students to write richer and more coherent stories by providing discussion (Gelmini-Hornsby, Ainsworth, \& O'Malley, 2011). In addition, digital stories prepared with the group help students to show better autonomy and enable more positive emotional experiences compared to individual digital stories (Liu et al., 2018). This study focuses on examining the effect of CDST on creative writing and socialemotional learning. The next section is devoted to the relationship between CDST and creative writing and social emotional learning, respectively.

\section{CDST and creative writing}

Encouraging creativity is important for everyone in terms of making life worth living and helping the self-realisation of individuals (Lee, 2019). The production of fictional narratives or written presentations is defined as creative writing (Nettle, 2009). Creative writing is not only a complex problem-solving activity, it is a process in which language is used to reflect, discover and express one's own experiences in a unique, creative and meaningful way (Vass et al., 2008). Factors such as observation, explanation, production, imagination, intrinsic motivation, and perseverance play key roles in the creative writing process (Barbot et al., 2012).

It is noteworthy that research in recent years has not adequately addressed digital technologies to support creative writing (Connolly \& Burn, 2019). The process of digital storytelling begins with the writing process of scriptwriting, and it can be argued that this can provide a suitable environment for encouraging creative writing skills. Through digital storytelling, students can creatively apply how to write the story and how to combine it using technology (Miller, 2010). Digital storytelling allows students to produce a multi-modal artefact that is very similar 
to the texts they encounter through the media as part of their daily lives (Hafner $\&$ Miller, 2011). Also, DST makes students feel the sense of writing and that students can develop themselves in the field of story writing with creative ideas (Liu et al., 2011). Various studies have demonstrated that digital storytelling improves writing skills (Green, 2011; Sarıca \& Usluel, 2016). However, writing is not a lonely activity, even if it is undertaken by one person (Rojas-Drummond, Albarrán, \& Littleton, 2008). It can be argued that there is a gap in the literature regarding the effect of collaborative digital stories on writing and creative writing skills. Writing is a sociocultural process, given that its learning takes place where designed by society (Rojas-Drummond et al., 2008). Building an artefact as a group and examining its effect on creative writing skills can help gain insight into the potential of the CDST. As a matter of fact, it is stated that CDST positively affects students' creativity (Rubino et al., 2018; Perez et al., 2016).

\section{CDST and social-emotional learning}

Although parents and teachers want schools to support their ability to be lifelong learners who can love, work and act as responsible members of the community, these values are not sufficiently integrated into the education system (Cohen, 2006). Concerns about the vulnerability of children and young people to social and psychological problems and the role of schools in overcoming such risks have led to the spread of efforts to make children more socially and emotionally competent (Hoffman, 2009). Social-emotional learning is the process of understanding and managing the emotions of children and adults, setting positive goals and achieving them, feeling empathy, establishing positive relationships and making responsible decisions to maintain them (CASEL, 2020). According to CASEL (2017), there are five competencies in social-emotional learning: self-awareness, social awareness, responsible decision making, self-management, relationship skills. DST has the potential to provide a suitable environment for social emotional learning skills. Especially in collaborative studies, students can develop more sense of belonging and cohesion in their groups (Harfitt, 2012). Borges, Kirkham, Deardoff, \& Moore (2012) showed that when collaborative work is used as a teaching strategy, university students significantly increase their ability to manage their emotions. It has been determined that the students included in digital story writing participate and exhibit a positive attitude towards collaboration (Ranieri \& Bruni, 2013). Some studies examine the effect of digital story preparation on emotional intelligence (Pieterse \& Quilling, 2011). It has been observed that CDST affects the development of students' social-emotional skills positively (Perez et al., 2018). 


\section{Acta Educationis Generalis \\ Volume 11, 2021, Issue 2}

\section{The present study}

This study aimed to examine the effect of CDST on creative writing and socialemotional learning skills. The following research questions are formulated:

RQ1. Is there a significant difference between the creative writing and socialemotional learning pre-test and post-test scores of the students in the experimental and control groups?

RQ2. Is there a significant difference between the creative writing and socialemotional post-test scores of the students between the experimental and control groups?

\section{Methodology}

\subsection{Participants}

The study was carried out in the academic year 2017-2018. 60 students attending the fourth grade of a primary school participated in the study. The control group consisted of 30 students (14 females and 16 males), and the experimental group was also 30 students (15 female and 15 male students). Before the research began, ethical approval was received from the university ethics committee. In addition, an information meeting about the research was held with the parents of the students. All of the parents filled in their voluntary consent forms and allowed their children to participate in the study. The study took place in four classes in the fourth grade of an elementary school in Turkey. The first author of this study works as a classroom teacher at the school where the implementation was made. The activities in the experimental and control groups were carried out by the first author in appropriate time periods considering the class schedules.

\subsection{Study design}

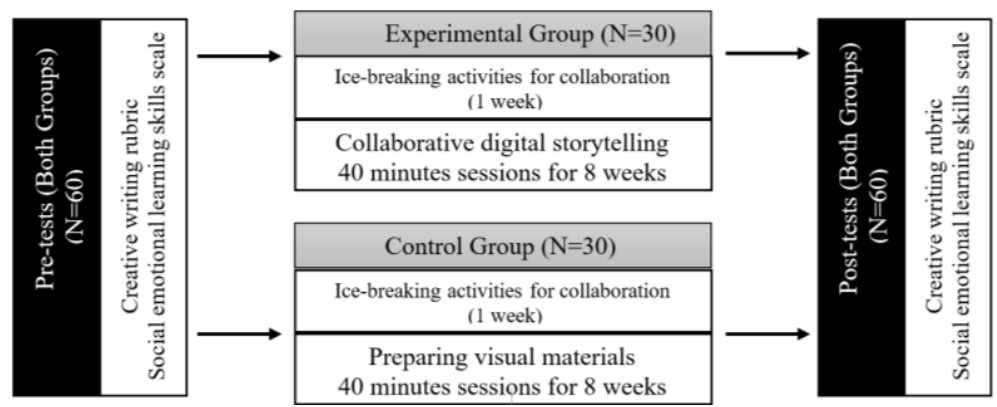

Figure 1. The study design.

In the study there were pre-test and post-test control groups. A quasiexperimental design was used, in which the experimental group was assigned a 
collaborative digital story, and the control group the task of preparing a visual presentation. Creative writing scores (Öztürk, 2007) and social-emotional learning skill scores (Kabakçı \& Owen, 2010) were collected from the experimental and control groups before and after the implementation. The study design is shown in Figure 1.

In the first week of the research, pre-tests were given after informing students about the studies to be performed. In the second week of the process, students were divided into heterogeneous groups, and ice-breaking activities were carried out by all students in the experimental and control groups to form a team identity. Starting from the third week, the experimental group students collaborated in groups on digital stories. The control group students also worked in groups to prepare a visual presentation per the curriculum.

\subsubsection{Experimental group}

Starting from the third week of the implementation process, students in the experimental group started to prepare collaborative digital stories.

(1) In the third week, students were first informed about digital storytelling and what they should do in this process. During the presentation, how the digital story is made, what it is and what should be considered was discussed with the students. Then, the students were asked to find a story subject based on their common life as a group. Students were given a week to find the topic of the digital story they would write, by making a joint decision with the other students in their group.

(2) The students formed a story circle in the fourth week. Since the application was group work, the students shared what topic to choose and what they wanted to tell in their stories. After reaching a common decision within the group, they told the story they had created to the classroom teacher (the first author of this study). Then the story was written as a group.

(3) In the fifth week, the students focused on planning the visuals that would be used in the stories. Their stories have been turned into worksheets with three columns. The sequence number is written in the first column, the sentence to be used in the story is placed in the second column, and the relevant image is described in the third column. In addition, members of the group took notes on who would vocalise each sentence in the story. Group members created the worksheets by reviewing the lines they wanted to add or remove. Figure 2 shows a storyboard belonging to one of the collaborative groups. Since one of the students in this group has diabetes, the story is about this student and the experiences of his classmates. 


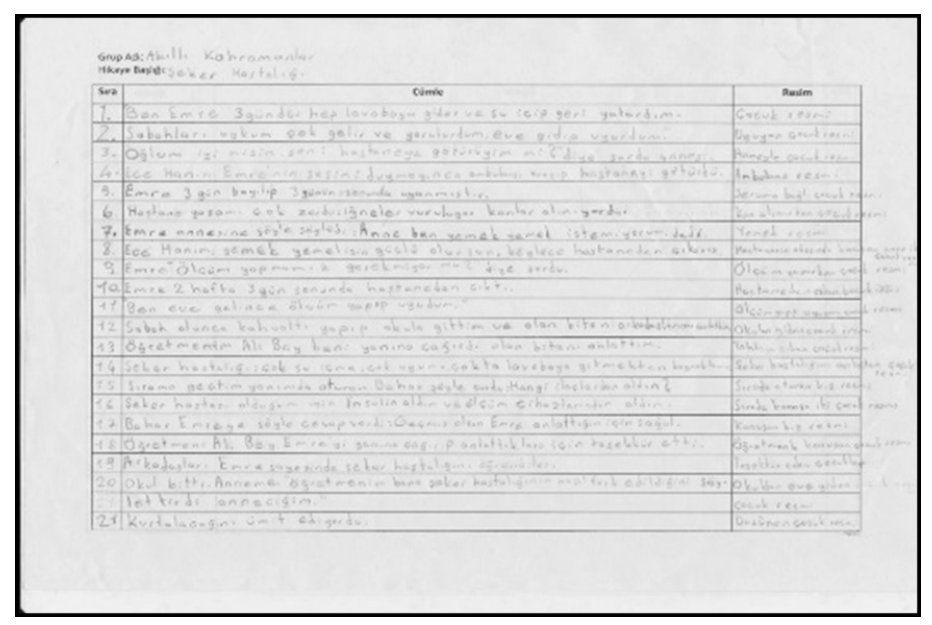

Figure 2. Example of a storyboard.

(4) The students came together to create the visuals they had determined about the lines on the worksheet during the sixth week as part of the pre-production works in the process of the digital story creation. The groups gathered the images they needed from various sources. In some groups, drawings were made by students with talent within the group.

(5) From the seventh week onwards, the students combined the pictures and stories they made in their groups using the Photo Story 3 program. In the eighth week, they recorded their voices using the Microsoft Photo Story 3 program. All the students in the group took part in the vocalisation stage. DST preparation processes in the Photo Story 3 program are given in Figure 3.

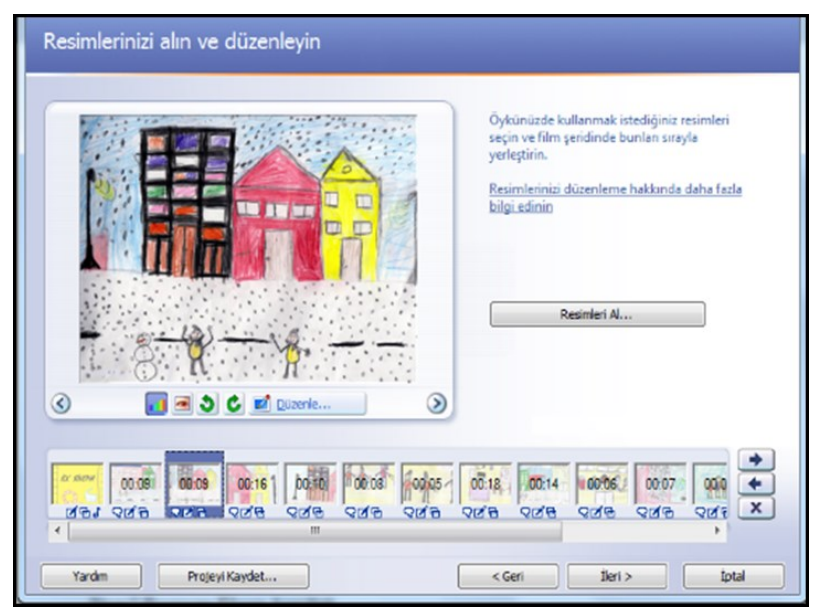

Figure 3. Story production process. 
6) In the ninth week, students added text and selected effects with the program they had used to create an effective digital story. In the tenth week, they added music with the help of their teacher. Since the study was a collaborative work, the students carried out a division of labour among themselves in the groups they formed. While creating a digital story, each student took tasks according to their own wishes and abilities. In the post-production stage of the process, the studies conducted were checked again and the areas that were deemed missing were handled under the guidance of the researcher. The digital story products that emerged in the last step of the digital story creation process were shared via the smart board and watched as a whole class (Figure 4).

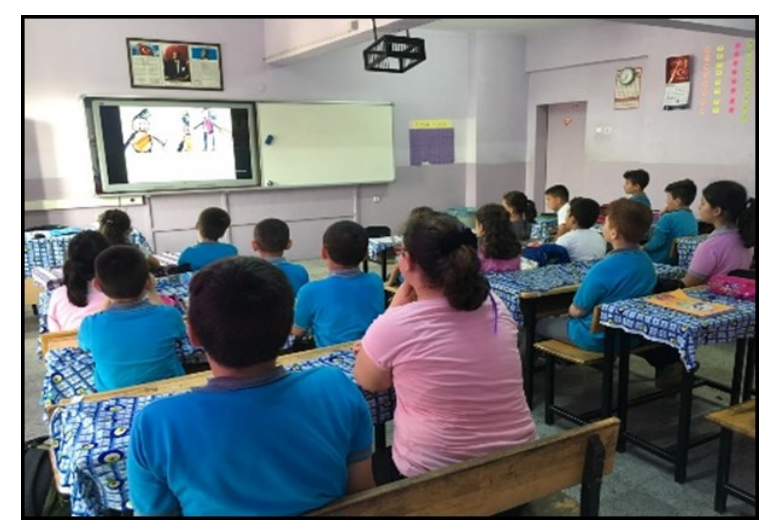

Figure 4. Story sharing stage.

\subsubsection{Control group}

In the third week of the implementation process, the process of preparing a poster in the control group started, in accordance with the curriculum. In the process, students collaborated and created the poster of their group with their friends. Various examples of visual materials that had been made before were shown to the students. The students planned how to prepare their visual presentations week by week. While some students drew pictures for the visual presentation they were creating, other students searched on the internet and found pictures related to their subjects. They took the colour printouts of these pictures and made the cutting, editing and pasting operations in the work section. The students prepared the materials related to the topics they had determined and presented them to the class on boards.

\subsection{Instruments}

\subsubsection{Creative Writing Rubric}

The writing activities of the students were scored with the Creative Writing Rubric developed by Öztürk (2007). Students created themes primarily for free 
writing. These themes were determined by the students as adventure, animals, friendship, space, nature and sharing. The students completed the writing study by choosing a subject according to their interests and wishes. For the post-test, the writing studies of students on the same subjects were scored with the Creative Writing Rubric, which is composed of eight sub-dimensions: (a) originality of ideas, (b) fluency of thoughts, (c) flexibility of thoughts, (d) word richness (selection), (e) sentence structure, (f) organisation (introduction to writing, development and outcome), (g) writing style, (h) compliance with grammar rules. There are values between 1 and 5 points in each sub-dimension. Thus, a student can get at least 8 and at most 40 points from this rubric.

\subsubsection{Social-emotional learning skills scale}

The Social-emotional Learning Skills Scale developed by Kabakçı and Owen (2010) was used to measure social-emotional learning skills. The data of the students were collected face to face using paper and pencil. Due to the young age of the students in this process, necessary explanations were made and sufficient time was given. There were 40 items on a 4-point Likert scale $(1=$ It does not fit me at all, $2=$ It does not fit me much, $3=$ It fits me a lot, $4=$ It completely fits me). The items were in four factors: problem solving, communication, increasing self-value and coping with stress. Cronbach's alpha coefficient was calculated as 0.88 for the total scores of the scale. Confirmatory factor analysis fit indices were found as RMSEA $=.036, \mathrm{GFI}=.90, \mathrm{CFI}=.96$, $\mathrm{AGFI}=.89, \mathrm{NFI}=.92, \mathrm{NNFI}=.96, \mathrm{SRMR}=.049 . \mathrm{A}$ minimum score of 40 and a maximum of 160 can be obtained from the scale. The scale can be applied both individually and as a group within an average of 15 minutes. In this study, the scale was applied individually.

\subsection{Data analysis}

In the study, paired samples t-test and single factor ANCOVA analysis were used and effect size ( $\eta 2)$ and Cohen's d were calculated. For the covariance analysis, the assumptions about the regression slopes between the groups, the normal distribution, and the equality of variance were examined. Regarding the scores obtained from the creative writing and social-emotional learning skills scale, the regression coefficients were examined for the pre-test and post-test scores (Table 1).

Table 1

Regression curves for creative writing and social-emotional learning scores

\begin{tabular}{rrrrrrr}
\hline Dependent & Source & Sum of & df & \multicolumn{1}{c}{ Mean } & \multicolumn{1}{c}{ S } & $p$ \\
Variable & Squares & & $\underline{\text { Square }}$ & & \\
Creative Writing Pre-test & 939.848 & 1 & 939.848 & 144.834 & 0.000 \\
Group*pre-test & 9.279 & 1 & 9.279 & 1.430 & 0.237 \\
\hline
\end{tabular}




\begin{tabular}{llrrrrr}
\hline & Error & 363.391 & 56 & 6.489 & & \\
& Corrected Total & 2020.183 & & & & \\
Social- & Pre-test & 4621.063 & 1 & 4621.063 & 54.691 & 0.000 \\
Emotional & Group*pre-test & 223.946 & 1 & 223.946 & 2.650 & 0.109 \\
Learning & Error & 4731.633 & 56 & 84.493 & & \\
& Corrected Total & 12282.183 & & & & \\
\hline
\end{tabular}

Accordingly, the interaction of the group and the pre-test was not significant (creative writing: $\mathrm{p}=0.237, \mathrm{p}>0.05$; social-emotional learning: $\mathrm{p}=0.109, \mathrm{p}>0.05$ ). For normality, skewness and kurtosis statistics are examined and presented in Table 2.

Table 2

\begin{tabular}{lllllr}
\multicolumn{6}{l}{ Skewness and kurtosis statistics } \\
\hline \multirow{2}{*}{ Creative } & Group & Test & $\underline{N}$ & $\frac{\text { Skewness }}{-0.473}$ & $\frac{\text { Kurtosis }}{1.612}$ \\
Writing & Experimental & Pre-test & 30 & 0.957 & 1.081 \\
& Control & & 30 & 0.349 & -0.045 \\
& Experimental & Post-test & 30 & 0.785 & 1.117 \\
Social- & Control & & 30 & -0.275 & -0.343 \\
emotional & Experimental & Pre-test & 30 & -0.454 & 0.905 \\
Learning & Control & & 30 & -0.685 & -0.156 \\
& Experimental & Post-test & 30 & -0.432 & -0.608 \\
\hline
\end{tabular}

A Levene test was performed for the equality of variances, the creative writing scores for the pre-test scores $[\mathrm{F}(1,58)=0.016, \mathrm{p}>0.05]$; for writing post-test scores $[\mathrm{F}(1,58)=0.333, \mathrm{p}>0.05]$; for social-emotional learning skills pre-test scores $[F(1,58)=2.472, p>0.05]$; and $[F(1,58)=2.669, p>0.05$ for post-test scores. This showed that the variances of the groups are equal in relation to all measurements.

\section{Results}

\subsection{Findings related to the first research question}

The first research question is formulated as: "Is there a significant difference between the creative writing and social-emotional learning skills pre-test and post-test scores of the students in the experimental and control groups?" The mean, standard deviation, $\mathrm{t}, \mathrm{p}$ and effect size values of the students in the experimental and control groups regarding the pre-test and post-test scores of the dependent variables are given in Table 3, where it is seen that there is an increase in the creative writing and social-emotional learning skills scores of both the experimental and control groups. According to the t-test results for dependent groups, an increase between pre-test and post-test scores were found 


\section{Acta Educationis Generalis \\ Volume 11, 2021, Issue 2}

significant for creative writing in both experimental $(\mathrm{t}(29)=8.623 ; \mathrm{p}=0,000)$ and control group $(\mathrm{t}(29)=5.259 ; \mathrm{p}=0.000)$.

When the calculated effect size values are examined, it is seen that there is a large effect for the experimental group (Cohen's $\mathrm{d}=0.88$ ) and a medium effect (Cohen's d $=0.54$ ) for the control group (Cohen, 1988). A statistically significant difference was found between pre-test and post-test scores in both experimental $(\mathrm{t}(29)=2.518 ; \mathrm{p}=0,018)$ and control groups for social-emotional learning skills $(\mathrm{t}(29)=3.934 ; \mathrm{p}=0,000)$. It can be interpreted that the effect size is small for both in experimental (Cohen's $\mathrm{d}=0.42$ ) and control group (Cohen's $\mathrm{d}=0.42$ ) for social-emotional learning.

Table 3

Results for paired - samples t-test

\begin{tabular}{|c|c|c|c|c|c|c|c|c|c|}
\hline & \multirow[t]{2}{*}{ Group } & \multirow[t]{2}{*}{$\underline{N}$} & \multicolumn{2}{|c|}{ Pre-test } & \multicolumn{2}{|c|}{ Post-test } & \multirow[t]{2}{*}{$\underline{t}$} & \multirow[t]{2}{*}{$p$} & \multirow{2}{*}{$\begin{array}{l}\text { Effect } \\
\text { size (d) }\end{array}$} \\
\hline & & & $\underline{M}$ & $\underline{S D}$ & $\underline{M}$ & $\underline{S D}$ & & & \\
\hline Crea & Experimental & 30 & $2 \overline{3.97}$ & $\overline{4.21}$ & $2 \overline{8.07}$ & $\overline{5.05}$ & 8.623 & 0.000 & 0.88 \\
\hline & Con & 30 & 18.77 & 4.41 & 21.17 & 4.42 & 5.259 & 0.000 & 0.54 \\
\hline Soc.-Em. & Experimental & 30 & 127.12 & 11.03 & 131.50 & 9.82 & 2.518 & 0.018 & 0.42 \\
\hline $\begin{array}{l}\text { Learning } \\
\text { Skills }\end{array}$ & Control & 30 & 118.53 & 17.66 & 126.07 & 17.65 & 3.934 & 0.000 & 0.42 \\
\hline
\end{tabular}

\subsection{Findings related to the second research problem}

The second research question is formulated as: "Is there a significant difference between the creative writing and social-emotional learning post-test scores of students between experiment and control groups?". Before the findings related to this research question were presented, pre-test scores of the groups were examined with the independent group t-test. There was a significant difference in creative writing pre-test scores between the experimental and control groups $(\mathrm{t}(58)=4.671 ; \mathrm{p}=.000)$. This indicated that the pre-test scores of the students in the experimental group were significantly higher than the control group before the implementation process. In addition, a significant difference was found in the social-emotional learning pre-test scores of the groups $(\mathrm{t}(58)=2.262 ; \mathrm{p}=.027)$, where it was seen that the pre-test scores of the students in the experimental group were significantly higher than the control group. When pre-test scores were kept constant, a single factor covariance analysis (ANCOVA) was conducted to examine whether the collaborative digital story preparation process had a significant effect on the post-test scores of the groups. In Table 4, the posttest scores of the groups, corrected according to the pre-test scores, are included. 
Table 4

Post-test scores of the groups and post-test scores corrected according to pretest scores

\begin{tabular}{lllcccc}
\hline & & & Post-test & \multicolumn{3}{c}{ Corrected post-test } \\
Creative & Group & $\underline{N}$ & $\underline{M}$ & $\underline{\underline{S}}$ & $\underline{M}$ & $\underline{S E}$ \\
Writing & Control & 30 & 28.07 & 0.77 & 25.65 & 0.80 \\
Social- & Experimental & 30 & 21.17 & 0.51 & 23.59 & 0.51 \\
emotional & Control & 30 & 131.50 & 1.79 & 128.31 & 1.74 \\
Learning & & & & & & \\
\hline
\end{tabular}

ANCOVA analysis results to test whether the observed difference between the corrected creative writing scores of the groups is significant are given in Table 5.

Table 5

ANCOVA results for creative writing post-test scores corrected according to the pre-test scores of the groups

\begin{tabular}{|c|c|c|c|c|c|c|}
\hline & Type III & & & & & \\
\hline Source & Sum of Squares & $\underline{d f}$ & Mean Square & $\underline{F}$ & $\underline{p}$ & $\underline{\eta}^{2}$ \\
\hline Pre-test (regression) & 6883.790 & 1 & 933.36 & $14 \overline{2} .76$ & 0.000 & 0.715 \\
\hline Group (Post-test) & 11.912 & 1 & 46.35 & 7.09 & 0.010 & 0.111 \\
\hline Error & 4955.580 & 57 & 6.53 & & & \\
\hline Corrected Total & 11851.280 & 59 & & & & \\
\hline
\end{tabular}

According to the ANCOVA results, there was a significant difference between the creative writing post-test scores of the groups, $F(1,57)=7.09, p<0.05$. In other words, the experimental process had an impact on creative writing. It is seen that the effect size value is calculated as $\eta 2=0.111$. Therefore, the experimental process has been found to have a moderate effect. The results of the ANCOVA analysis conducted to test whether the observed difference between the corrected scores of the groups for social-emotional learning is significant is given in Table 6 .

Table 6

ANCOVA results for social-emotional learning post-test scores corrected according to the pre-test scores of the groups

\begin{tabular}{|c|c|c|c|c|c|c|}
\hline & Type III & & & & & \\
\hline Source & Sum of Squares & $d f$ & Mean Square & $\underline{F}$ & $\underline{p}$ & $\underline{\eta}^{2}$ \\
\hline Pre-test (regression) & 6883.790 & 1 & 6883.790 & $79 . \overline{179}$ & 0.000 & 0.581 \\
\hline Group (Post-test) & 11.912 & 1 & 11.912 & 0.137 & 0.713 & 0.002 \\
\hline Error & 4955.580 & 57 & 86.940 & & & \\
\hline Corrected Total & 11851.280 & 59 & & & & \\
\hline
\end{tabular}


According to the ANCOVA results, there was no significant difference between the social-emotional learning skills post-test scores of the groups, $F(1$, $57)=0.137, \mathrm{p}>0.05$. In other words, it was concluded that the experimental process did not have effect on social-emotional learning skills.

\section{Discussion}

This study aimed to investigate the effect of collaborative digital storytelling on the creative writing and social-emotional learning skills of primary school fourth grade students. In this study, which was carried out following a quasiexperimental design, social-emotional learning skills were measured at the beginning and end of the process, and students' writing studies were evaluated using a rubric. When the experimental and control groups were compared, it was concluded that the experimental process had a moderate effect in favour of the experimental group on the creative writing skill. When the related literature is examined, there are studies supporting these results. Coutinho (2010) claimed that digital storytelling enhances creativity, learning motivation and 21st century communication and technology skills. Moreover, DST involves a process rooted in verbal culture, where the high-level experience reaches a different level of literacy through storytelling and story-building efforts (Şimşek et al., 2018). Schmoelz (2018) identified specific stages of digital storytelling as very important for providing co-creativity, especially the story production stage which enables the co-creative flow experience. A study where digital storytelling was used to support the writing skills of students concluded that in the written products of students, the appropriate title was determined, attention was paid to the order of event; the logical integrity was not impaired (Ciğerci \& Gültekin, 2017). According to Daigle (2008), digital storytelling requires writing skills and creativity. It can be used effectively where DST is considered as a means of developing narrative knowledge (Garcia \& Rossiter, 2010).

When the social-emotional learning skills were examined, there was an improvement in both the experimental group and the control group when the implementation process was completed. However, the experimental process did not have a significant effect on social-emotional learning skills. Robin (2006) stated that sharing digital stories in various web environments would provide an opportunity to criticise the work, and that social learning and emotional intelligence can improve. Yüksel, Robin, and McNeil (2011) also found that in the process of digital storytelling, students develop empathy, social interaction, and communication skills. In addition, applications related to digital storytelling contribute to the development of cooperative skills and creativity of students by doing group work (Jenkins \& Lonsdale, 2007). Although it has been stated in the literature that CDST supports the development of social-emotional learning skills, this study has not been proven experimentally. On the other hand, there was an improvement between the pre-test and post-test scores in both the experimental and control groups. This may be because the students in both 
groups performed a collaborative study. Future studies may focus on the indepth understanding of the process by conducting a qualitative study within the context of CDST and social-emotional learning skills.

Robin (2006) claimed that there is not enough time for implementations when digital storytelling is carried out. Indeed, it takes a lot of time to put together the necessary components for digital story creation and to prepare the story. Similarly, it was stated that it takes a great deal of time to practise the process of digital story creation (Coutinho, 2010) and that the time is not sufficient, especially for writing studies (Kulla-Abbott, 2006). However, there are also studies to create digital stories faster and more easily by studying collaboratively (Karakoyun \& Kuzu, 2016). It can be stated that the process of time management is easier within the scope of CDST application in this study.

In this study, students were involved in various tasks in the collaborative digital story creation process. With their interests and abilities, they fulfilled these tasks more eagerly. From time to time they searched for solutions to the problems they faced. It can be said that this situation encourages learning by acting collaboratively. In this context, it is stated that digital storytelling improves students' collaboration and communication skills and that these students are willing to help each other in the face of various problems (Sadik, 2008). Digital storytelling creates an atmosphere of solidarity that offers storytelling as an amateur form and presents verbal, cognitive and affective skills (Şimşek et al., 2018). As a matter of fact, it has been stated that students can help each other and improve their collaboration and solidarity skills during activities related to digital storytelling (Karakoyun \& Kuzu, 2016). It is emphasised that the process of digital story creation improves technology skills through the use of computer programs and technological tools (Robin, 2008; Yüksel et al., 2011). Robin (2006) explained that during the digital story creation, students improved their technology literacy by combining multimedia elements such as text, picture and sound through various programs. In addition, Karakoyun \& Kuzu (2016) stated that information literacy has improved by researching which information students search for stories. As a result, it can be stated that the CDST process provides experience in using computers and the internet by performing the tasks such as accessing the information over the internet, creating a sound recording, taking photos and editing, choosing music and organising them on the software. In studies on the digital story, educators and researchers working on this topic stated that digital storytelling is an effective application. Many studies show that with digital storytelling, students actively participate in the learning process and increase their meaningful learning, thus obtaining more skills than traditional approaches (Robin, 2008; Wang \& Zhan, 2010; Yoon, 2013).

\section{Conclusion}

As a result of this study, it can be concluded that CDST improved students' creative writing skills and can be used in language lessons. In the study, it was 


\section{Acta Educationis Generalis \\ Volume 11, 2021, Issue 2}

observed by the researchers that CDST was more advantageous in terms of time and application. On the other hand, the study has some limitations. Indeed, comparing individual and collaborative DST processes is beyond the scope of this study. On the other hand, future research may focus on comparing individual and collaborative digital storytelling. Other research may examine the effect of CDST on the attitudes of students towards collaborative work. This study was designed with a quantitative method, and research can be conducted in the future using a qualitative or mixed method that addresses students 'experiences, difficulties, teachers and parents' views in the process. Qualitative studies examining the interaction of students with each other in digital story preparation processes with collaborative groups can contribute to the literature.

\section{References}

Barbot, B., Tan, M., Randi, J., Santa-Donato, G., \& Grigorenko, E. L. (2012). Essential skills for creative writing: Integrating multiple domain-specific perspectives. Thinking Skills and Creativity, 7, 209-223.

Borges, N. J., Kirkham, K., Deardorff, A. S., \& Moore, J. A. (2012). Development of emotional intelligence in a team-based learning internal medicine clerkship. Medical Teacher, 34(10), 802-806.

CASEL (2017). Social Emotional Learning Competencies. Retrieved from https://casel.org/wpcontent/uploads/2019/12/CASEL-Competencies.pdf

CASEL (2020). What is SEL? Retrieved from_https://casel.org/what-is-sel/

Cohen, J. (1988). Statistical Power Analysis for the Behavioral Sciences (2nd ed.). New Jersey: Hillsdale: Lawrence Earlbaum Associates.

Cohen, J. (2006). Social, emotional, ethical, and academic education: Creating a climate for learning, participation in democracy, and well-being. Harvard Educational Review, 76(2), 201-237.

Connolly, S., \& Burn, A. (2019). The story engine: Offering an online platform for making 'unofficial' creative writing work. Literacy, 53(1), 30-38.

Coutinho, C. (2010). Storytelling as a strategy for integrating technologies into the curriculum: An empirical study with post-graduate teachers. In D. Gibson, \& B. Dodge (Eds.), Proceedings of Society for Information Technology \& Teacher Education International Conference 2010 (pp. 3795-3802). Chesapeake, VA: AACE.

Ciğerci, F. M., \& Gültekin, M. (2017). Use of digital stories to develop listening comprehension skills. Issues in Educational Research, 27(2), 252-268.

Çiçek, M. (2018). Investigatıng the Effects of Digital Storytelling Use in Sixth-Grade Science Course: A Mixed Method Research Study (Unpublished doctoral thesis). Ankara: Middle East Technical University.

Daigle, B. A. (2008). Digital Storytelling as a Literacy-Based Intervention for a Sixth Grade Student with Autism Spectrum Disorder: An Exploratory Case Study (Unpublished doctoral thesis). Baton Rouge, La: Louisiana State University.

Duveskog, M., Tedre, M, Sedano, C., \& Sutinen, E. (2012). Life planning by digital storytelling in a primary school in rural Tanzania. Educational Techonology \& Society, 15(4), 225-237.

Garcia, P. A., \& Rossiter, M. (2010). Digital storytelling as narrative pedagogy. In D. Gibson, \& B. Dodge (Ed.), Proceedings of Society for Information Technology \& Teacher Education International Conference 2010 (pp. 1091-1097). Chesapeake, VA: AACE. 


\section{Acta Educationis Generalis \\ Volume 11, 2021, Issue 2}

Gelmini-Hornsby, G., Ainsworth, S., \& O’Malley, C. (2011). Guided reciprocal questioning to support children's collaborative storytelling. Internatinal Journal of Computer-Supported Collaborative Learning, 6(4), 577-600.

Gömleksiz, M. N., \& Pullu, E. K. (2017). The effect of digital stories developed by using Toondoo on students' academic achievement and attitudes. International Periodical for The Languages, Literature and History of Turkish Or Turkic, 12(32), 95-110.

Green, M. R. (2011). Teaching the Writing Process through Digital Storytelling in Preservice Education (Unpublished doctoral dissertation). USA: University of Texas A\&M.

Grigsby, Y., Theard-Griggs, C., \& Lilly, C. (2015). (Re)Claiming voices: Digital storytelling and second language learners. Acta Technologica Dubnicae, 5(1), 60-67. https://doi.org/10.1515/ atd-2015-0034

Hafner, C. A., \& Miller, L. (2011). Fostering learner autonomy in English for science: A collaborative digital video project in a technological learning environment. Langue Learning \& Technology, 15(3), 68-86.

Harfitt, G. J. (2012). How class size reduction mediates secondary students' learning: Hearing the pupil voice. Asia Pacific Education Review, 13(2), 299-310.

Hoffman, D. M. (2009). Reflecting on social emotional learning: A critical perspective on trends in the United States. Review of Educational Research, 79(2), 533-556.

Hung, C. M., Hwang, G. J., \& Huang, I. (2012). A project-based digital storytelling approach for improving students' learning motivation, problem-solving competence and learning achievement. Educational Technology \& Society, 15(4), 368-379.

Jenkins, M., \& Lonsdale, J. (2007). Evaluating the effectiveness of digital storytelling for student reflection. In ASCILITE Conference (pp. 440-444). Singapore.

Kabakçı, Ö. F., \& Owen, F. K. (2010). A study of development of Social Emotional Learning Skills Scale. Education and Science, 35(157), 152-166.

Karakoyun, F., \& Kuzu, A. (2016). The investigation of preservice teachers' and primary school students' views about online digital storytelling. European Journal of Contemporary Education, 15(1), 51-64.

Kulla-Abbott, T. M. (2006). Developing Literacy Practices through Digital Storytelling (Unpublished doctoral thesis). St. Louis: University of Missouri.

Kurudayığlu, M., \& Bal, M. (2014). The use of digital storytelling in mother language education. Sakarya University Faculty Education Journal, 28, 74-95.

Laborda, J. G. (2009). Using webquests for oral communication in English as a foreign language for tourism studies. Educational Technology \& Society, 12(1), 258-270.

Lee, S. M. (2019). Her story or their own stories? Digital game-based learning, student creativity, and creative writing. ReCALL, 31(3), 238-254.

Liu, C. C., Liu, K. P., Chen, W. H., Lin, C. P., \& Chen, G. D. (2011). Collaborative storytelling experiences in social media: Influence of peer-assistance mechanisms. Computers \& Education, 57, 1544-1556.

Liu, M. C., Huang, Y. M., \& Xu, Y. H. (2018). Effects of individual versus group work on learner autonomy and emotion in digital storytelling. Association for Educational Communications and Technology, 66, 1009-1028.

Miller, L. C. (2010). Make Me a Story: Teaching Writing through Digital Storytelling. USA: Stenhouse Publishers.

Nettle, D. (2009). The evolution of creative writing. In S. B. Kaufman, \& J. C. Kaufman (Eds.), The psychology of creative writing (pp. 101-116). New York: Cambridge University Press.

Nishioka, H. (2016). Analyzing language development in a collaborative digital storytelling project: Sociocultural perspectives. System, 62, 39-52.

Öztürk, E. (2007). Evaluating the Creative Writing Skills of the 5th Grades of Primary Education (Unpublished doctoral thesis). Ankara: Gazi University. 


\section{Acta Educationis Generalis \\ Volume 11, 2021, Issue 2}

Perez, M. E. D. M., Martinez, L. V., \& Pineiro, M. R. N. (2016). Social and creative skills promoted with the collaborative design of digital storytelling in the classroom. Digital Education Review, 30, 30-52.

Perez, M. E. D. M., Martinez, L. V., \& Pineiro, M. R. N. (2018). Instructors' perception about emotional and creative schoolchildren development, coming from collaborative design of digital storytelling. Facultad de Education, 21, 345-374.

Pieterse, G., \& Quilling, R. (2011). The impact of digital story-telling on trait emotional intelligence (EI) amongst adolescents in South Africa - A case study. Procedia - Social and Behavioral Sciences, 28, 156-163.

Ranieri, M., \& Bruni, I. (2013). Mobile storytelling and informal education in a suburban area: A qualitative study on the potential of digital narratives for young second-generation immigrants. Learning Media and Technology, 38(2), 217-235.

Robin, B. (2006). The educational uses of digital storytelling. In C. Crawford (Ed.), Proceedings of Society for Information Technology \& Teacher Education International Conference (pp. 709-716). Chesapeake, VA: AACE.

Robin, B. (2008). Digital storytelling: A powerful technology tool for the 21 st century classroom. Theory into Practice, 47(3), 220-228.

Rojas-Drummond, S. M., Albarrán, C. D., \& Littleton, K. S. (2008). Collaboration, creativity and the co-construction of oral and written texts. Thinking Skills and Creativity, 3, 177-191.

Rubino, I., Barberis, C., \& Malnati, G. (2018). Exploring the values of writing collaboratively through a digital storytelling platform: A mixed-methods analysis of users' participation, perspectives and practices. Interactive Learning Environments, 26(7), 882-894.

Sadik, A. (2008). Digital storytelling: A meaningful technology-integrated approach for engaged student learning. Educational Technology Research and Development, 56(4), 487-506.

Sarıca, H. Ç., \& Usluel, Y. K. (2016). The effect of digital storytelling on visual memory and writing skills. Computers \& Education, 94, 298-309.

Schmoelz, A. (2018). Enabling co-creativity through digital story-telling in education. Thinking Skills and Creativity, 28, 1-13.

Şimşek, B., Usluel, Y., Sarıca, H., \& Tekeli, P. (2018). A critical approach to digital storytelling usage in educational context in Turkey. Educational Technology: Theory and Practice, 8(1), 158-186.

Vass, E., Littleton, K., Miell, D., \& Jones, A. (2008). The discourse of collaborative creative writing: Peer collaboration as a context for mutual inspiration. Thinking Skills and Creativity, 3, 192-202.

Wang, S., \& Zhan, H. (2010). Enhancing teaching and learning with digital storytelling. International Journal of Information and Communication Technology Education, 6(2), 7687.

World Economic Forum (2015). Global Information Technology Report. Retrieved from http://www3.weforum.org/docs/WEFUSA_NewVisionfor Education_Report2015.pdf

World Economic Forum (2016). Global Information Technology Report. Retrieved from http://www3.weforum.org/docs/WEF_Future_of_Jobs.pdf

Yang, Y. T. C., \& Wu, W. C. I. (2012). Digital storytelling for enhancing student academic achievement, critical thinking, and learning motivation: A year-long experimental study. Computers \& Education, 59(2), 339-352.

Yoon, T. (2013). Are you digitized? Ways to provide motivation for ells using digital storytelling. International Journal of Research Studies in Educational Technology, 2(1), 25-34.

Yüksel, P., Robin, B., \& McNeil, S. (2011). Educational uses of digital storytelling all around the World. Society for Information Technology \& Teacher Education International Conference (pp. 1264-1271). Association for the Advancement of Computing in Education (AACE). Tennessee. 